\section{BRAZIULAN JOURNAL \\ OF MEDICAL AND BIOLOGICAL RESEARCH}

www.bjournal.com.br
ISSN 1414-431X

Volume 45 (12) 1102-1340 December 2012

\section{BIOMIDICAL SCIENCES}

AND

CLINICAL INVESTIGATION

Braz J Med Biol Res, December 2012, Volume 45(12) 1255-1261

doi: 10.1590/S0100-879X2012007500143

Pamidronate for the treatment of osteoporosis secondary to chronic cholestatic liver disease in Wistar rats

F.A. Pereira, R. Mattar, I. Facincani, H.L.A. Defino, L.N.Z. Ramalho, V. Jorgetti, J.B. Volpon and F.J.A. de Paula

The Brazilian Journal of Medical and Biological Research is partially financed by

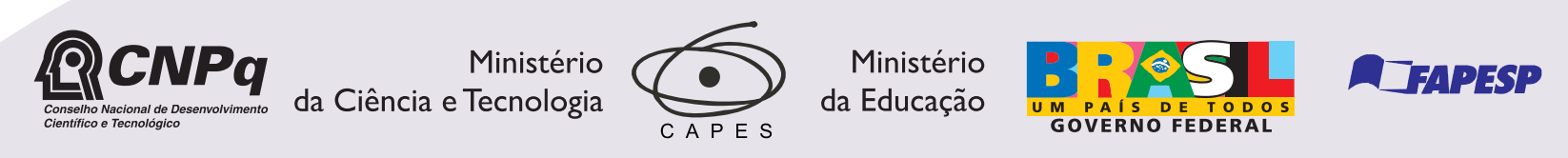

Sciezo
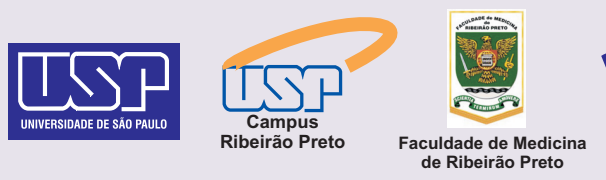

Institutional Sponsors

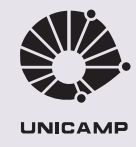

SHIMADZU

$\oplus$ UNICAMP

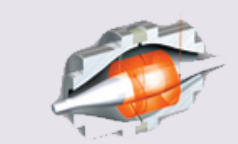

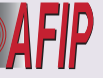

Associaçaco Associaçăo
Fundo
de Incentivo à Pesquisa 


\title{
Pamidronate for the treatment of osteoporosis secondary to chronic cholestatic liver disease in Wistar rats
}

\author{
F.A. Pereira ${ }^{1}$, R. Mattar ${ }^{1 \dagger}$, I. Facincani², H.L.A. Defino ${ }^{3}$, L.N.Z. Ramalho ${ }^{4}$, \\ V. Jorgetti ${ }^{5}$, J.B. Volpon ${ }^{3}$ and F.J.A. de Paula ${ }^{1}$ \\ ${ }^{1}$ Departamento de Clínica Médica, Faculdade de Medicina de Ribeirão Preto, \\ Universidade de São Paulo, Ribeirão Preto, SP, Brasil \\ ${ }^{2}$ Departamento de Pediatria e Neonatologia, Faculdade de Medicina de Ribeirão Preto, \\ Universidade de São Paulo, Ribeirão Preto, SP, Brasil \\ ${ }^{3}$ Departamento de Biomecânica, Medicina e Reabilitação do Aparelho Locomotor, \\ Faculdade de Medicina de Ribeirão Preto, Universidade de São Paulo, Ribeirão Preto, SP, Brasil \\ ${ }^{4}$ Departamento de Patologia, Faculdade de Medicina de Ribeirão Preto, \\ Universidade de São Paulo, Ribeirão Preto, SP, Brasil \\ ${ }^{5}$ Departamento de Nefrologia, Faculdade de Medicina, Universidade de São Paulo, São Paulo, SP, Brasil
}

\begin{abstract}
Osteoporosis is a major complication of chronic cholestatic liver disease (CCLD). We evaluated the efficacy of using disodium pamidronate $(1.0 \mathrm{mg} / \mathrm{kg}$ body weight) for the prevention (Pr) or treatment ( $\mathrm{Tr}$ ) of cholestasis-induced osteoporosis in male Wistar rats: sham-operated (Sham $=12)$; bile duct-ligated $(\mathrm{Bi}=15)$; bile duct-ligated animals previously treated with pamidronate before and 1 month after surgery $(\operatorname{Pr}=9)$; bile duct-ligated animals treated with pamidronate 1 month after surgery $(\operatorname{Tr}=9)$. Rats were sacrificed 8 weeks after surgery. Immunohistochemical expression of IGF-I and GH receptor was determined in the proximal growth plate cartilage of the left tibia. Histomorphometric analysis was performed in the right tibia and the right femur was used for biomechanical analysis. Bone material volume over tissue volume (BV/TV) was significantly affected by CCLD (Sham $=$ $18.1 \pm 3.2 v s \mathrm{Bi}=10.6 \pm 2.2 \%)$ and pamidronate successfully increased bone volume. However, pamidronate administered in a preventive regimen presented no additional benefit on bone volume compared to secondary treatment $(\mathrm{BV} / \mathrm{TV}: \mathrm{Pr}=39.4 \pm$ $12.0 ; \mathrm{Tr}=41.2 \pm 12.7 \%)$. Moreover, the force on the momentum of fracture was significantly reduced in $\operatorname{Pr}$ rats $(\mathrm{Sham}=116.6$ $\pm 23.0 ; \mathrm{Bi}=94.6 \pm 33.8 ; \mathrm{Pr}=82.9 \pm 22.8 ; \mathrm{Tr}=92.5 \pm 29.5 \mathrm{~N} ; \mathrm{P}<0.05$, Sham vs $\mathrm{Pr}$ ). Thus, CCLD had a significant impact on bone histomorphometric parameters and pamidronate was highly effective in increasing bone mass in CCLD; however, preventive therapy with pamidronate has no advantage regarding bone fragility.
\end{abstract}

Key words: Hepatic osteodystrophy; Osteoporosis pathogenesis; Growth factors; Biomechanics; Animal models; Pamidronate

\section{Introduction}

Hepatic osteodystrophy is a generic term used to identify bone diseases associated with the complex metabolic disturbance linked to liver diseases, especially chronic cholestatic liver disease (CCLD) (1). Osteoporosis is the major bone complication of CCLD. Multiple factors contribute to bone loss in CCLD and all can be easily recognized at the end stage of chronic liver disease (malnutrition, hypogonadism, vitamin $D$ deficiency, insulin-like growth factor-I (IGF-I) deficiency, and cholestasis) (2). However, decreased production of endocrine IGF-I by the liver $(3,4)$, as well as paracrine/ autocrine IGF-I expression in the bone microenvironment (5), has been shown to be an early crucial determinant of bone impairment in CCLD.

Bisphosphonates are potent inhibitors of bone resorption, usually indicated for patients with clinically significant osteoporosis, namely postmenopausal women with a bone mineral density T-score below -2.5 or with pathological bone fracture. In addition, according to the American College of

Correspondence: F.J.A. de Paula, Departamento de Clínica Médica, Faculdade de Medicina de Ribeirão Preto, USP, Av. Bandeirantes, 3900, 14049-900 Ribeirão Preto, SP, Brasil. Fax: +55-16-3633-6695. E-mail: fjpaula@fmrp.usp.br

†'n memoriam

Received May 12, 2012. Accepted August 31, 2012. Available online September 14, 2012. Published December 17, 2012. 
Rheumatology, it is also indicated for the primary prevention of glucocorticoid-induced osteoporosis (6). In this context, attempts to extend the list of diseases, which would benefit from primary prevention with bisphosphonate treatment must be counterbalanced by considering an array of peculiarities and potentially negative issues: a) the mechanism behind bone loss, i.e., decreased bone formation or increased bone resorption, b) concerns exist about how long bone remodeling could artificially be inhibited by anti-resorptive drugs without serious impairment of bone repairing capacity (7), and c) the effectiveness of pharmacologic therapy in the prevention of osteoporosis in young individuals (8).

Bone mineral density assessment represents a landmark in the clinical investigation and diagnosis of osteoporosis. However, this surrogate end point represents a partial evaluation of bone strength and an increase in bone mineral density does not necessarily mean a reduction of fracture risk. Animal models, especially of rodents, have made an extensive contribution to the advancement of the understanding of the mechanistic role of several factors in the etiopathogenesis of osteoporosis $(9,10)$. Thus, translational research in mice and rats is a fundamental tool for the development of new drugs and the design of new treatment schemes. However, an important limitation of the study of osteoporosis in small animal models is the lack of fracture due to bone insufficiency (11). Biomechanical tests have been a reasonable option to circumvent this limitation and are used extensively for the experimental analysis of bone strength $(12,13)$.

In this scenario, the major objective of the present study was to evaluate the beneficial effect of disodium pamidronate (pamidronate) as primary prevention therapy for hepatic osteodystrophy in CCLD. Rats submitted to bile duct ligation (BDL) surgery received pamidronate before and 1 month after surgery (primary prevention) or only 1 month after surgery. The results obtained with these two groups were compared to those obtained with the sham-operated group and another group submitted only to BDL. Biochemical evaluation of mineral metabolism and liver function was performed, the expression of IGF-I and of growth hormone receptor (GHR) in the growth plate was evaluated in all animals and bone histomorphometry of the tibia and biomechanical assays of the femur were also analyzed.

\section{Material and Methods}

All experimental designs and procedures were approved by the Animal Research Ethics Committee of the Faculdade de Medicina de Ribeirão Preto, USP. Forty-five 2-month-old male Wistar rats, housed individually at $25^{\circ} \mathrm{C}$ on a $12: 12-\mathrm{h}$ light-dark cycle, were used in this study. They were strictly pair-fed a laboratory diet provided by Nuvital (Nuvilab CR1; Brazil) containing $22 \%$ protein, $53 \%$ carbohydrate, and $4.5 \%$ lipid. Animals had free access to water. Rats subjected to BDL surgery were used as reference. The study was comprised of 4 groups of male Wistar rats weighing
150-175 g: a) sham-operated rats (Sham, $N=12$ ); b) rats subjected to bile duct ligation surgery $(\mathrm{Bi}, \mathrm{N}=15)$; c) rats subjected to bile duct ligation surgery plus pamidronate as primary prevention therapy administered before and 1 month after the procedure ( $\mathrm{Pr}, \mathrm{N}=9$ ); d) rats subjected to bile duct ligation surgery plus pamidronate as conventional therapy, administered 1 month after the procedure $(\mathrm{Tr}, \mathrm{N}=$ 9). The protocol was repeated 3 times, each comprised of 4 rats in the Sham group and 6 rats in the groups submitted to BDL. Three rats in the Bi group and 9 rats in the Pr and Tr groups died during the period of observation. All groups were followed for 2 months after surgery; pamidronate was injected intraperitoneally at the dose of $1.0 \mathrm{mg} / \mathrm{kg}$ body weight. Vehicle ( $0.9 \%$ sodium chloride) was injected in Sham and Bi groups. At the end of the second month, all rats submitted do BDL showed clinical manifestations of cholestatic disease.

\section{Bile duct ligation technique}

Anesthesia was induced by intraperitoneal injection of $2.5 \%$ tribromoethanol (Aldrich, USA; $250 \mathrm{mg} / \mathrm{kg}$ body mass). A median laparotomy was performed and the common bile duct was exposed and doubly ligated as described previously. In Sham rats, the procedure consisted of exposure of the liver hilum, which was gently mobilized with a sterile cotton applicator. After surgery, the BDL groups were injected intramuscularly once a week with vitamin $\mathrm{K}(8 \mathrm{mg} / \mathrm{kg}$ body weight). Sham rats were injected with an equivalent volume of saline infusion $(0.9 \%$ sodium chloride).

\section{Biochemical analysis}

Blood collections were performed at baseline $(2 \mathrm{~mL}$ from the tail) and at sacrifice when $7 \mathrm{~mL}$ blood was drawn from the left ventricle. The samples were maintained on ice and then centrifuged at $4^{\circ} \mathrm{C}$. Serum aliquots were immediately used for the determination of albumin, total calcium, inorganic phosphorus, bilirubin, alanine aminotransferase $(\mathrm{ALT})$, and aspartate aminotransferase (AST).

\section{Biomechanical evaluation}

Biomechanical tests. Frozen femora were thawed at room temperature for $2 \mathrm{~h}$ before testing. Mechanical tests were performed on intact right femora using a destructive three-point bending procedure. The femur was placed supine on two round bars at a distance of $20 \mathrm{~mm}$ in a mechanical testing machine (10,000 N, EMIC, Brazil) and deflected by a notched bar on the opposite side of the bone. The descending speed of the notched bar was $1 \mathrm{~mm} / \mathrm{min}$. Maximal force and stiffness were determined from force/ deflection plots.

\section{Histological assessment}

Quantitative static and dynamic bone histomorphometry was performed as described previously (5). To measure bone formation rates, tetracycline label $(20 \mathrm{mg} / \mathrm{kg}$ body 
weight) was injected intraperitoneally 7 and 2 days before sacrifice. The right tibia was removed and dehydrated in ethanol, infiltrated and embedded without demineralization in methyl methacrylate. Undecalcified sections were cut at a thickness of $5 \mu \mathrm{m}$ and mounted unstained for dynamic measurements. Consecutive sections were stained with toluidine blue to quantify bone cells. The histomorphometric indexes are reported according to the standardized nomenclature recommended by the American Society of Bone and Mineral Research (14).

Bone specimens for immunohistochemical analysis were processed as previously described (5). Briefly, bone samples were sectioned at the growth plate at a thickness of $4 \mu \mathrm{M}$ from paraffin blocks containing representative samples and mounted on poly-L-lysine-coated slides. Nonspecific protein binding was blocked with normal serum (Novostain Universal Super ABC Kit; Novocastra Laboratories, UK) for $30 \mathrm{~min}$. The sections were then incubated with primary monoclonal antibodies specific for IGF-I (1:200; American Diagnostic, USA) and GHR (1:100, American Diagnostic). Next, the slides were incubated with the avidin-biotin-peroxidase complex (Novostain Universal Super ABC Kit), counterstained with Harris hematoxylin, dehydrated, and mounted with Permount (Biomeda, USA). As negative controls, all specimens were incubated with a control antibody under identical conditions. The preparations for each marker were evaluated at random in at least 10 representative high-power fields (40X magnification), and graded according to their intensities and percentage of positive cells. Cells were designated as positive when they displayed a distinct brown cytoplasm staining. Semiquantitative expression was scored as follows: 0 , no stained cells; + , fewer than $10 \%$ positive cells;,$++ 10-50 \%$ positive cells;,$+++>50 \%$ positive cells.

\section{Statistical analysis}

Data are reported as means \pm SEM. Statistical significance was determined using ANOVA followed by the Tukey test for multiple comparisons, and the Pearson correlation coefficient was employed for the analysis of correlation between parametric variables using the GraphPad Prism software (GraphPad Prism, USA)

\section{Results}

There was no significant difference in body weight between groups either at baseline (Sham $=164.3 \pm 3.5 ; \mathrm{Bi}=$ $164.9 \pm 2.7 ; \operatorname{Pr}=165.3 \pm 2.3 ; \operatorname{Tr}=166.3 \pm 1.9 \mathrm{~g})$ or at the end of the experiment (Sham $=483.6 \pm 55.3 ; \mathrm{Bi}=458.7$ $\pm 60.4 ; \mathrm{Pr}=438.8 \pm 62.4 ; \mathrm{Tr}=448.8 \pm 68.4 \mathrm{~g}$ ). All groups exhibited significant weight gain during the 2 months of observation $(P<0.001)$.

Sham-operated animals exhibited no variation in serum albumin levels during the experiment, while the other groups showed decreased levels of serum albumin at the end of the study. At sacrifice, the three groups submitted to BDL showed lower serum levels of albumin than the Sham group, $\mathrm{P}<0.01$ (Table 1), whereas hepatic enzymes [gamma-glutamyl transpeptidase ( $\mathrm{G} T$ ), alkaline phosphatase, ALT, and AST] and bilirubin increased significantly in these 3 groups compared to the Sham group (Table 1). No significant differences in the levels of hepatic enzymes were observed between the groups submitted to surgery for ligation of the bile duct, i.e., hepatic enzymes were similar

Table 1. Biochemical evaluation of rats under basal conditions and at 60 days after sham surgery (Sham), bile duct ligation (BDL) surgery $(\mathrm{Bi}), \mathrm{BDL}$ surgery plus pamidronate prevention therapy ( $\mathrm{Pr}$, basal and 30 days after surgery), and BDL surgery plus pamidronate therapy $(\operatorname{Tr}) 30$ days after surgery.

\begin{tabular}{|c|c|c|c|c|c|c|c|c|}
\hline & \multicolumn{2}{|c|}{ Sham $(N=12)$} & \multicolumn{2}{|c|}{$\mathrm{Bi}(\mathrm{N}=15)$} & \multicolumn{2}{|c|}{$\operatorname{Pr}(N=9)$} & \multicolumn{2}{|c|}{$\operatorname{Tr}(\mathrm{N}=9)$} \\
\hline & Basal & 60 days & Basal & 60 days & Basal & 60 days & Basal & 60 days \\
\hline Albumin (g/L) & $38 \pm 1$ & $37 \pm 1$ & $37 \pm 1$ & $28 \pm 1^{*}$ & $38 \pm 1$ & $30 \pm 4^{*}$ & $39 \pm 1$ & $29 \pm 4^{*}$ \\
\hline $\begin{array}{l}\text { Corrected calcium } \\
(\mathrm{mM})\end{array}$ & $2.40 \pm 0.10$ & $2.38 \pm 0.13$ & $2.38 \pm 0.13$ & $2.48 \pm 0.18$ & $2.35 \pm 0.08$ & $2.43 \pm 0.13$ & $2.33 \pm 0.10$ & $2.38 \pm 0.22$ \\
\hline Phosphorus (mM) & $1.81 \pm 0.16$ & $1.84 \pm 0.16$ & $1.87 \pm 0.19$ & $1.97 \pm 0.26$ & $1.74 \pm 0.19$ & $1.91 \pm 0.32$ & $1.84 \pm 0.13$ & $1.91 \pm 0.23$ \\
\hline үGT ((U/L) & $7.8 \pm 0.3$ & $7.9 \pm 0.3$ & $7.6 \pm 0.5^{\#}$ & $46.3 \pm 4.6^{\star *}$ & $7.4 \pm 0.6^{\#}$ & $48.9 \pm 5.2^{* *}$ & $7.7 \pm 0.4^{\#}$ & $47.8 \pm 4.2^{\star *}$ \\
\hline $\begin{array}{l}\text { Alkaline } \\
\text { phosphatase }(U / L)\end{array}$ & $118.0 \pm 4.5$ & $115.0 \pm 5.5$ & $115.0 \pm 3.6^{\# \#}$ & $1654.0 \pm 114.9^{* * *}$ & $116.0 \pm 4.6^{\# \#}$ & $1754.0 \pm 122.6^{* * *}$ & $117.0 \pm 0.4^{\# \#}$ & $1689.0 \pm 119.3^{* * *}$ \\
\hline ALT (U/L) & $28.0 \pm 3.5$ & $26.0 \pm 4.5$ & $26.5 \pm 3.6^{\#}$ & $174.7 \pm 6.6^{\star *}$ & $27.7 \pm 4.6^{\#}$ & $193.7 \pm 8.6^{* *}$ & $25.4 \pm 2.4^{\#}$ & $178.4 \pm 7.6^{\star *}$ \\
\hline AST (U/L) & $32.5 \pm 4.5$ & $30.5 \pm 5.5$ & $31.5 \pm 4.6^{\#}$ & $144.6 \pm 7.6^{* *}$ & $33.7 \pm 3.4^{\#}$ & $156.6 \pm 6.6^{* *}$ & $33.6 \pm 3.8^{\#}$ & $154.7 \pm 8.6^{\star \star}$ \\
\hline Total bilirubin $(\mu \mathrm{M})$ & $10.3 \pm 0.17$ & $12.0 \pm 0.17$ & $8.6 \pm 0.20^{\#}$ & $152.2 \pm 17.1^{* *}$ & $10.3 \pm 0.34^{\#}$ & $156.6 \pm 30.8^{* *}$ & $10.3 \pm 0.17^{\#}$ & $153.9 \pm 29.7^{\star *}$ \\
\hline Direct bilirubin $(\mu \mathrm{M})$ & $6.8 \pm 0.17$ & $8.6 \pm 0.17$ & $6.9 \pm 0.34^{\#}$ & $133.4 \pm 15.4^{\star *}$ & $6.8 \pm 3.4^{\#}$ & $147.1 \pm 15.4^{* *}$ & $6.8 \pm 0.17^{\#}$ & $143.6 \pm 15.4^{\star *}$ \\
\hline Indirect bilirubin $(\mu \mathrm{M})$ & $3.5 \pm 0.17$ & $3.4 \pm 0.17$ & $1.7 \pm 0.17^{\#}$ & $18.8 \pm 10.3^{* *}$ & $3.5 \pm 0.17 \#$ & $9.5 \pm 0.5^{* *}$ & $3.5 \pm 0.17^{\#}$ & $10.3 \pm 5.1^{* *}$ \\
\hline
\end{tabular}

Data are reported as means \pm SEM. YGT = gamma-glutamyl transpeptidase; $\mathrm{ALT}=$ alanine aminotransferase; $\mathrm{AST}=$ aspartate aminotransferase. ${ }^{*} \mathrm{P}<0.01,60$ days $\mathrm{Bi}, \mathrm{Pr}$, Tr compared to 60 days Sham; ${ }^{*} \mathrm{P}<0.001,60$ days $\mathrm{Bi}, \mathrm{Pr}$, $\mathrm{Tr}$ compared to 60 days Sham; ${ }^{*} \mathrm{P}<0.001$, basal Bi, Pr, Tr compared to 60 days Bi, Pr, Tr, respectively; ${ }^{* * *} \mathrm{P}<0.0001,60$ days Bi, $\mathrm{Pr}$, Tr compared to 60 days Sham; ${ }^{\# \#} \mathrm{P}<0.0001$, basal $\mathrm{Bi}, \mathrm{Pr}$, $\mathrm{Tr}$ compared to 60 days $\mathrm{Bi}$, $\mathrm{Pr}$, $\mathrm{Tr}$, respectively (ANOVA followed by the Tukey test for multiple comparisons). 
in animals treated with vehicle or pamidronate. There were no significant differences in serum levels of corrected total calcium and phosphorus between groups (Table 1).

CCLD affected negatively bone microarchitecture; 2 months after BDL, bone material volume over tissue volume (BV/TV) and trabecular thickness were decreased, whereas trabecular separation was enhanced in the Bi group. On the other hand, pamidronate reversed all of these alterations and both groups subjected to preventive (Pr) and secondary ( $\mathrm{Tr}$ ) pamidronate treatment showed significantly greater BV/TV and trabecular thickness and significantly lower trabecular separation than the Sham and Bi groups (Table 2). Bone formation parameters were not significantly affected by cholestasis. However, pamidronate induced a reduction in osteoblast number (e.g., osteoblast surface/ bone surface: Sham $=11.2 \pm 4.7 ; \mathrm{Bi}=12.4 \pm 8.4 ; \mathrm{Pr}=5.6$ $\pm 1.9 ; \mathrm{Tr}=6.9 \pm 3.0 \% ; \mathrm{P}<0.05$, Bi vs $\mathrm{Pr}$ ) and in osteoblast activity (e.g., bone formation rate/bone surface: Sham = 46.3 \pm 36.8; $\mathrm{Bi}=36.5 \pm 15.4 ; \mathrm{Pr}=9.5 \pm 6.3 ; \mathrm{Tr}=11.1 \pm 3.6$ $\mu \mathrm{m}^{2} \cdot\left(\mu \mathrm{m}^{3}\right)^{-1} \cdot$ day $^{-1} ; \mathrm{P}<0.05$, Sham vs Pr, Sham vs Tr, Bi vs $\mathrm{Pr})$. The bone resorption in Bi was similar to that observed in Sham. However, pamidronate induced high suppression of the number of osteoblasts and of osteoblastic activity in the tibiae (Table 2).

There were no significant differences in IGF-I or GHR expression in the tibial growth plate cartilage of the four groups (Table 3).

Table 4 shows that the maximum force necessary to fracture bone was not significantly higher in the Sham group compared to both the group with obstructed bile duct without treatment and to the group with obstructed bile duct receiving pamidronate as treatment. In the cholestasis group and in the cholestasis group receiving pamidronate treatment the lowest force necessary to induce fracture

Table 2. Histomorphometric evaluation of the proximal tibial metaphysis at 60 days after sham surgery (Sham), bile duct ligation (BDL) surgery (Bi), BDL surgery plus pamidronate prevention therapy ( $\mathrm{Pr}$, basal and 30 days after surgery), and BDL surgery plus pamidronate therapy ( $\mathrm{Tr}$ ) 30 days after surgery.

\begin{tabular}{|c|c|c|c|c|}
\hline & Sham $(N=12)$ & $\mathrm{Bi}(\mathrm{N}=15)$ & $\operatorname{Pr}(N=9)$ & $\operatorname{Tr}(\mathrm{N}=9)$ \\
\hline \multicolumn{5}{|l|}{ Structure } \\
\hline BV/TV $(\%)$ & $18.1 \pm 3.2$ & $10.6 \pm 2.2^{\star \star}$ & $39.4 \pm 12.0^{*}$ & $41.2 \pm 12.7^{*}$ \\
\hline Tb.Th $(\mu \mathrm{m})$ & $71.7 \pm 8.8$ & $66.6 \pm 11.8$ & $81.8 \pm 6.5$ & $71.0 \pm 12.1$ \\
\hline Tb.N (/mm) & $2.6 \pm 0.6$ & $1.6 \pm 0.2^{\star *}$ & $4.9 \pm 1.4^{*}$ & $5.8 \pm 1.7^{*}$ \\
\hline Tb.Sp $(\mu \mathrm{m})$ & $337.0 \pm 88.2^{\star \star \star}$ & $566.8 \pm 75.1$ & $135.6 \pm 53.0^{\#}$ & $112.5 \pm 52.0^{\#}$ \\
\hline \multicolumn{5}{|l|}{ Formation } \\
\hline OV/TV $(\%)$ & $0.6 \pm 0.4^{\# \#}$ & $0.4 \pm 0.3^{\# \#}$ & $0.9 \pm 0.6$ & $1.2 \pm 0.6$ \\
\hline OV/BV (\%) & $3.8 \pm 1.8$ & $4.2 \pm 3.0$ & $2.0 \pm 1.1$ & $3.2 \pm 1.5$ \\
\hline OS/BS (\%) & $34.8 \pm 16.5$ & $35.2 \pm 24.2$ & $19.0 \pm 9.9$ & $27.4 \pm 9.4$ \\
\hline Ob.S/BS (\%) & $11.2 \pm 4.7$ & $12.4 \pm 8.4$ & 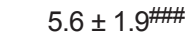 & $6.9 \pm 3.0$ \\
\hline O.Th $(\mu \mathrm{m})$ & $7.7 \pm 1.7$ & $7.1 \pm 0.9$ & $8.3 \pm 1.6$ & $8.6 \pm 2.0$ \\
\hline N.Ob/B.Pm (/mm) & $3.9 \pm 1.6$ & $4.1 \pm 2.1$ & $2.3 \pm 0.9$ & $3.1 \pm 1.3$ \\
\hline MAR ( $\mu \mathrm{m} /$ day $)$ & $0.57 \pm 0.3$ & $0.71 \pm 0.09$ & $0.42 \pm 0.12^{+}$ & $0.49 \pm 0.09^{+}$ \\
\hline BFR/BS $\left(\mu \mathrm{m}^{2} \cdot\left(\mu \mathrm{m}^{3}\right)^{-1} \cdot \mathrm{day}^{-1}\right)$ & $46.3 \pm 36.8$ & $36.5 \pm 15.4^{+++}$ & $9.5 \pm 6.3^{++}$ & $11.1 \pm 3.6^{++}$ \\
\hline Aj.AR ( $\mu \mathrm{m} /$ day $)$ & $0.18 \pm 0.1$ & $0.29 \pm 0.1$ & $0.13 \pm 0.05 \pi$ & $0.14 \pm 0.07 \pi$ \\
\hline Mlt (day) & $49.8 \pm 29.7$ & $32.2 \pm 22.7$ & $71.2 \pm 31.9 \pi$ & $71.8 \pm 30.0 \pi$ \\
\hline \multicolumn{5}{|l|}{ Resorption } \\
\hline N.Oc/B.Pm (/mm) & $0.9 \pm 0.4$ & $1.1 \pm 0.3$ & $0.3 \pm 0.2$ & $0.4 \pm 0.3$ \\
\hline ES/BS (\%) & $5.4 \pm 2.7$ & $6.6 \pm 2.2$ & $2.0 \pm 1.5$ & $2.3 \pm 1.7$ \\
\hline Oc.S/BS (\%) & $4.1 \pm 2.0$ & $5.1 \pm 1.9$ & $1.3 \pm 0.8$ & $1.6 \pm 1.4$ \\
\hline
\end{tabular}

Data are reported as means \pm SEM. $\mathrm{BV}=$ bone volume; $\mathrm{TV}=$ tissue volume; $\mathrm{Tb}$.th $=$ trabecular thickness; Tb.N = trabecular number; Tb.sp = trabecular separation; OV = osteoid volume; OS = osteoid surface; $\mathrm{BS}=$ bone surface; Ob.S = osteoblast surface; $\mathrm{O} . \mathrm{Th}=$ osteoid thickness; $\mathrm{N} . \mathrm{Ob}=$ osteoblast number; B.Pm = bone perimeter; MAR = mineral apposition rate; BFR = bone formation rate; Aj.AR = adjusted apposition rate; $\mathrm{Mlt}=$ mineralization lag time; $\mathrm{N} . \mathrm{OC}=$ osteoclast number; $\mathrm{ES}=$ eroded surface; Oc.S = osteoclast surface. ${ }^{*} \mathrm{P}<0.001$, Pr and Tr compared to Sham; ${ }^{* *} \mathrm{P}<0.001$, Bi compared to $\operatorname{Pr}$ and TR; ${ }^{* *} \mathrm{P}<0.001$, Sham compared to $\mathrm{Bi}$, Pr and TR; ${ }^{\mathrm{P}}<0.001$, Pr and TR compared to $\mathrm{Bi}$; \# ${ }^{\mathrm{P}}<0.05$, Sham and $\mathrm{Bi}$ compared to $\mathrm{Tr}$; \#\# $<0.05$, Pr compared to $\mathrm{Bi}$; ${ }^{+} \mathrm{P}<0.05$, $\mathrm{Pr}$ and $\mathrm{Tr}$ compared to $\mathrm{Bi} ;{ }^{++} \mathrm{P}<0.05$, Pr and Tr compared to Sham; ${ }^{+++} \mathrm{P}<0.05$, Bi compared to $\operatorname{Pr}$; $\operatorname{TP}<0.05$, $\mathrm{Pr}$ and $\mathrm{Tr}$ compared to $\mathrm{Bi}$ (ANOVA followed by the Tukey test for multiple comparisons). 
Table 3. Insulin-like growth factor-I (IGF-I) and growth hormone receptor (GHR) expression in the proximal tibial metaphysis at 60 days after sham surgery (Sham), bile duct ligation (BDL) surgery (Bi), BDL surgery plus pamidronate prevention therapy ( $\operatorname{Pr}$, basal and 30 days after surgery), and BDL surgery plus pamidronate therapy ( $\operatorname{Tr}) 30$ days after surgery.

\begin{tabular}{|c|c|c|c|c|c|c|c|c|}
\hline & \multicolumn{2}{|c|}{ Sham $(N=12)$} & \multicolumn{2}{|c|}{$\mathrm{Bi}(\mathrm{N}=15)$} & \multicolumn{2}{|c|}{$\operatorname{Pr}(N=9)$} & \multicolumn{2}{|c|}{$\operatorname{Tr}(\mathrm{N}=9)$} \\
\hline & IGF-I & GHR & IGF-I & GHR & IGF-I & GHR & IGF-I & GHR \\
\hline 0 & $4(33.3)$ & $8(66.6)$ & $7(46.7)$ & $9(60.0)$ & $3(33.3)$ & $3(33.3)$ & $6(66.6)$ & $4(44.4)$ \\
\hline+ & 7 (58.3) & $4(33.3)$ & $4(26.7)$ & $3(20.0)$ & $1(11.1)$ & $6(66.6)$ & $3(33.3)$ & $5(55.6)$ \\
\hline++ & $1(8.3)$ & $0(0)$ & $4(26.7)$ & $3(20.0)$ & $5(55.6)$ & $0(0)$ & $0(0)$ & $0(0)$ \\
\hline+++ & $0(0)$ & $0(0)$ & $0(0)$ & $0(0)$ & $0(0)$ & $0(0)$ & $0(0)$ & $0(0)$ \\
\hline
\end{tabular}

Data are reported as number of animals with percent in parentheses. $(0)=$ no stained cells; $(+)=$ fewer than $10 \%$ positive cells; $(++)=10-50 \%$ positive cells; $(+++)=>50 \%$ positive cells.

was decreased to about the same level, 18.9 and $20.7 \%$, respectively, compared to control. In parallel, in the group that received pamidronate as a preventive scheme the force on the momentum of fracture was even more reduced $(29.0 \%$, $P<0.05)$.

\section{Discussion}

The present study showed that pamidronate used for primary prevention therapy, administered immediately before and 1 month after surgeryinduced cholestasis, enhances bone mass. However, primary prevention therapy had no additional advantage in comparison to conventional treatment (i.e., therapy initiation after established bone disease, 1 month after cholestasis). The improvement in bone microstructure of animals treated by primary prevention therapy was similar to the benefit observed in the group in which pamidronate treatment was started only after established bone disorder. Additionally, the force required to fracture bone from animals treated with primary prevention was lower than that required to fracture bone from animals treated with secondary prevention therapy.

Bisphosphonates decrease fracture risk in large part by reducing the rate of bone remodeling and associated microarchitectural bone deterioration as well as by increasing bone mass. Bone remodeling is the mechanism by which bone repairs microdamage and delivers calcium into the circulation $(15,16)$. Bone formation rates estimated by tetracycline labeling are reduced in patients on bisphosphonates. Most patients on bisphosphonates show reductions in remodeling to the range seen in healthy premenopausal women (17). The primary end-point required for Food and Drug Administration (FDA) approval of therapies for the treatment of postmenopausal osteoporosis is significant reduction in incident morphometric vertebral fractures over 3 years compared with placebo (18). The extensive experi-
Table 4. Biomechanical evaluation of the femur at 60 days after sham surgery Sham), bile duct ligation (BDL) surgery (Bi), BDL surgery plus pamidronate prevention therapy ( $\mathrm{Pr}$, basal and 30 days after surgery), and BDL surgery us pamidronate therapy (Tr) 30 days after surgery.

\begin{tabular}{lclll} 
& Sham $(\mathrm{N}=12)$ & $\mathrm{Bi}(\mathrm{N}=15)$ & $\operatorname{Pr}(\mathrm{N}=9)$ & $\operatorname{Tr}(\mathrm{N}=9)$ \\
\hline Length $(\mathrm{mm})$ & $39.4 \pm 3.1$ & $37.5 \pm 3.3$ & $39.0 \pm 1.4$ & $37.5 \pm 2.6$ \\
Ultimate load $(\mathrm{N})$ & $116.6 \pm 23.0$ & $94.6 \pm 33.8$ & $82.9 \pm 22.8^{*}$ & $92.5 \pm 29.5$ \\
Stiffness $(\mathrm{N} / \mathrm{mm})$ & $129.0 \pm 77.8$ & $90.3 \pm 52.4$ & $67.2 \pm 1.5$ & $72.6 \pm 7.6$ \\
\hline
\end{tabular}

Data are reported as means \pm SEM. ${ }^{*} \mathrm{P}<0.05$, Pr compared to Sham (ANOVA followed by the Tukey test for multiple comparisons).

ence accumulated in osteoporosis treatment involves postmenopausal women, showing severe densitometric bone loss or established osteoporosis, which means a previous history of fracture (19-21).

Currently, glucocorticoid-induced osteoporosis (GIO) is the sole clinical condition for which the use of bisphosphonates is advocated for primary prevention (6). This approach is based on the pathophysiology of $\mathrm{GIO}$, namely the occurrence of two distinct phases of bone loss, the first involving a fast bone remodeling rate and the second involving a slow process of bone loss. In GIO, the early use of a potent antiresorptive drug prevents the increment of bone resorption activity and bone loss. Although some studies have suggested that osteoporosis in CCLD is due to a combination of decreased bone formation and accelerated bone resorption $(22,23)$, most studies describe a more conspicuous impairment of bone formation $(24,25)$. Studies on hepatic osteodystrophy in humans have indicated that the most striking change in the profile of biochemical markers of bone remodeling is the reduction of osteocalcin, i.e., reduction in the activity of bone formation $(26,27)$. These data are supported by results obtained in histomorphometric evaluation in experimental models of CCLD (5) as well as in humans $(28,29)$.

In a previous study on 2-month-old Wistar rats, we 
have shown that four weeks after BDL surgery there are clear signs of osteoporosis determined by bone histomorphometry, expressed as decreased BV/TV and osteoblast number (5). In the present study, the previous evidence was replicated with a more severe pattern after 2 months of cholestasis. Additionally, we observed the efficiency of pamidronate in reversing the process of bone loss. Animals treated with pamidronate 1 month after BDL exhibited increased bone volume (BV/TV), as well as high trabecular thickness and trabecular number. On the other hand, histomorphometric data showed that there was no additional benefit when pamidronate was used for primary prevention, i.e., the improvement of bone structure was of the same magnitude as that observed when treatment was started only after established bone disease. Furthermore, the bone capacity to withstand mechanical stress was decreased in femur specimens from animals subjected to primary prevention treatment compared to those obtained from animals treated with the secondary regimen. Similar to our study, there are data showing that distinct bisphosphonates are able to prevent trabecular osteopenia in ovariectomy, a classical experimental model of osteoporosis $(13,30)$. These studies observed improvement in the ultimate force for bone fracture only in lumbar spine bone and, similar to our results, no effect was verified in long bones of animals subjected to bisphosphonate treatment $(13,30,31)$. Kippo et al. (31) suggested that in the rat the amount of cortical bone and external bone dimensions would contribute more to the structural strength of the femur than the amount and microarchitecture of trabecular bone. In addition to those studies, the present investigation showed that pamidronate used as preventive treatment may impair bone strength in rats submitted to surgically induced cholestasis. Femur from cholestatic rats submitted to preventive pamidronate treatment showed a decreased ultimate load for fracture and a trend to reduced stiffness. These results agree with previous data showing an inverse correlation between intraosseous concentration of pamidronate and ultimate load at failure and stiffness (32).

Other histomorphometric parameters indicate impairment of bone remodeling activity in the tibia from BDL rats subjected to preventive pamidronate therapy. Alteration in skeletal mineralization and decreased bone repairing capacity were demonstrated by an increased time required for mineralization and a concomitant decrement in the num-

\section{References}

1. Lopez-Larramona G, Lucendo AJ, Gonzalez-Castillo S, Tenias JM. Hepatic osteodystrophy: An important matter for consideration in chronic liver disease. World J Hepatol 2011; 3: 300-307.

2. Gasser RW. Cholestasis and metabolic bone disease - a clinical review. Wien Med Wochenschr 2008; 158: 553-557. ber of osteoclasts and on surface resorption area in BDL animals treated with pamidronate. Although the number of osteoblasts was not decreased in pamidronate-treated animals, these animals exhibited a lower bone formation rate. Taken together, these results indicate impaired turnover and accumulation of microcracks due to suppressed osteoclast-mediated bone resorption.

No difference in IGF-I or GHR expression in growth cartilage was detected between animals treated with both pamidronate regimens and vehicle. Most likely, this occurrence reflects the animals' age since no difference was also observed between sham-operated animals and the other three groups. In a previous study, we detected a significant decrease in IGF-I and GHR expression in 3-month-old Wistar rats submitted to BDL surgery. It is well known that the age-related decline in the expression of IGF-I is part of the maturation process (33). Thus, the different results are probably due to the distinct ages of the experimental rats. Liver-derived and autocrine/paracrine IGF-I are both crucial components for bone mass development and maintenance (34-36). In the present study, the serum levels of IGF-I were not measured, but liver-derived IGF-I is characteristically decreased in cholestatic diseases.

Therefore, the present study shows that pamidronate is highly effective in inducing an apparent improvement in bone microstructure in an experimental model of CCLD. The data also show that early pharmacological treatment used as primary prevention does not represent a better approach. Histomorphometric evaluation demonstrated that cholestatic animals submitted to a primary or secondary treatment regimen exhibit the same bone volume. However, bone strength tested by biomechanical assays showed a better capacity to resist mechanical stress in rats treated with a secondary regimen.

\section{Acknowledgments}

Rinaldo Mattar participated in the study design and made an important contribution to the development of this investigation. We thank Sebastião L. Brandão Filho, Sebastião Assis, Carlos Alberto Moro, Auristela de Melo Martins, Adalberto Vallada Verceze, Mauricio Rodrigues de Arantes, and Roni Charles Fabbris for technical help and laboratory assistance. Research supported by FAPESP (\#06/56890-0), CNPq, and FAEPA.
3. de Albuquerque Taveira AT, Fernandes MI, Galvao LC, Sawamura R, de Mello V, de Paula FJ. Impairment of bone mass development in children with chronic cholestatic liver disease. Clin Endocrinol 2007; 66: 518-523.

4. Taveira AT, Pereira FA, Fernandes MI, Sawamura R, Nogueira-Barbosa MH, Paula FJ. Longitudinal evaluation 
of hepatic osteodystrophy in children and adolescents with chronic cholestatic liver disease. Braz J Med Biol Res 2010; 43: 1127-1134.

5. Pereira FA, Facincani I, Jorgetti V, Ramalho LN, Volpon JB, Dos Reis LM, et al. Etiopathogenesis of hepatic osteodystrophy in Wistar rats with cholestatic liver disease. Calcif Tissue Int 2009; 85: 75-83.

6. Grossman JM, Gordon R, Ranganath VK, Deal C, Caplan L, Chen W, et al. American College of Rheumatology 2010 recommendations for the prevention and treatment of glucocorticoid-induced osteoporosis. Arthritis Care Res 2010; 62: 1515-1526.

7. Bachrach LK, Ward LM. Clinical review 1: Bisphosphonate use in childhood osteoporosis. J Clin Endocrinol Metab 2009; 94: 400-409.

8. Thornton J, Ashcroft D, O'Neill T, Elliott R, Adams J, Roberts $C$, et al. A systematic review of the effectiveness of strategies for reducing fracture risk in children with juvenile idiopathic arthritis with additional data on long-term risk of fracture and cost of disease management. Health Technol Assess 2008; 12: iii-xiv, 1.

9. Rosen CJ. Building bones by knocking down genes. Nat Med 2012; 18: 202-204.

10. Horton JA, Bariteau JT, Loomis RM, Strauss JA, Damron TA. Ontogeny of skeletal maturation in the juvenile rat. Anat $R e c$ 2008; 291: 283-292.

11. Turner AS. Animal models of osteoporosis - necessity and limitations. Eur Cell Mater 2001; 1: 66-81.

12. Peng Z, Tuukkanen J, Zhang H, Jamsa T, Vaananen HK. The mechanical strength of bone in different rat models of experimental osteoporosis. Bone 1994; 15: 523-532.

13. Kippo K, Hannuniemi R, Isaksson P, Lauren L, Osterman $T$, Peng $Z$, et al. Clodronate prevents osteopenia and loss of trabecular connectivity in estrogen-deficient rats. $J$ Bone Miner Res 1998; 13: 287-296.

14. Parfitt AM, Drezner MK, Glorieux FH, Kanis JA, Malluche $H$, Meunier PJ, et al. Bone histomorphometry: standardization of nomenclature, symbols, and units. Report of the ASBMR Histomorphometry Nomenclature Committee. J Bone Miner Res 1987; 2: 595-610.

15. Burr DB. Targeted and nontargeted remodeling. Bone 2002; 30: $2-4$.

16. Li J, Mashiba T, Burr DB. Bisphosphonate treatment suppresses not only stochastic remodeling but also the targeted repair of microdamage. Calcif Tissue Int 2001; 69: 281286.

17. Eriksen EF, Melsen F, Sod E, Barton I, Chines A. Effects of long-term risedronate on bone quality and bone turnover in women with postmenopausal osteoporosis. Bone 2002; 31: 620-625.

18. Miller PD. Anti-resorptives in the management of osteoporosis. Best Pract Res Clin Endocrinol Metab 2008; 22: 849868.

19. Black DM, Cummings SR, Karpf DB, Cauley JA, Thompson $D E$, Nevitt MC, et al. Randomised trial of effect of alendronate on risk of fracture in women with existing vertebral fractures. Fracture Intervention Trial Research Group. Lancet 1996; 348: 1535-1541.

20. Reginster J, Minne HW, Sorensen OH, Hooper M, Roux $\mathrm{C}$, Brandi ML, et al. Randomized trial of the effects of risedronate on vertebral fractures in women with established postmenopausal osteoporosis. Vertebral Efficacy with Rise- dronate Therapy (VERT) Study Group. Osteoporos Int 2000; 11: 83-91.

21. Black DM, Delmas PD, Eastell R, Reid IR, Boonen S, Cauley JA, et al. Once-yearly zoledronic acid for treatment of postmenopausal osteoporosis. N Engl J Med 2007; 356: 1809-1822.

22. Crawford BA, Kam C, Donaghy AJ, McCaughan GW. The heterogeneity of bone disease in cirrhosis: a multivariate analysis. Osteoporos Int 2003; 14: 987-994.

23. Monegal A, Navasa M, Guanabens N, Peris P, Pons F, Martinez de Osaba MJ, et al. Osteoporosis and bone mineral metabolism disorders in cirrhotic patients referred for orthotopic liver transplantation. Calcif Tissue Int 1997; 60: 148-154.

24. Capra F, Casaril M, Gabrielli GB, Stanzial A, Ferrari S, Gandini G, et al. Plasma osteocalcin levels in liver cirrhosis. Ital J Gastroenterol 1991; 23: 124-127.

25. Guanabens N, Pares A, Marinoso L, Brancos MA, Piera C, Serrano $S$, et al. Factors influencing the development of metabolic bone disease in primary biliary cirrhosis. Am J Gastroenterol 1990; 85: 1356-1362.

26. Chen CC, Wang SS, Jeng FS, Lee SD. Metabolic bone disease of liver cirrhosis: is it parallel to the clinical severity of cirrhosis? J Gastroenterol Hepatol 1996; 11: 417-421.

27. Goral V, Simsek M, Mete N. Hepatic osteodystrophy and liver cirrhosis. World J Gastroenterol 2010; 16: 1639-1643.

28. Jorge-Hernandez JA, Gonzalez-Reimers CE, Torres-Ramirez A, Santolaria-Fernandez F, Gonzalez-Garcia C, BatistaLopez JN, et al. Bone changes in alcoholic liver cirrhosis. A histomorphometrical analysis of 52 cases. Dig Dis Sci 1988; 33: 1089-1095.

29. Chappard D, Plantard B, Fraisse H, Palle S, Alexandre C, Riffat G. Bone changes in alcoholic cirrhosis of the liver. A histomorphometric study. Pathol Res Pract 1989; 184: 480485.

30. Toolan BC, Shea M, Myers ER, Borchers RE, Seedor JG, Quartuccio $\mathrm{H}$, et al. Effects of 4-amino-1-hydroxybutylidene bisphosphonate on bone biomechanics in rats. $J$ Bone Miner Res 1992; 7: 1399-1406.

31. Kippo K, Hannuniemi R, Lauren L, Peng Z, Isaksson P, Virtamo $\mathrm{T}$, et al. Clodronate prevents bone loss in aged ovariectomized rats. Calcif Tissue Int 1997; 61: 151-157.

32. Yang KH, Won JH, Yoon HK, Ryu JH, Choo KS, Kim JS. High concentrations of pamidronate in bone weaken the mechanical properties of intact femora in a rat model. Yonsei Med $J$ 2007; 48: 653-658.

33. Okuda S, Myoui A, Ariga K, Nakase T, Yonenobu K, Yoshikawa $\mathrm{H}$. Mechanisms of age-related decline in insulinlike growth factor-I dependent proteoglycan synthesis in rat intervertebral disc cells. Spine 2001; 26: 2421-2426.

34. Courtland HW, Elis S, Wu Y, Sun H, Rosen CJ, Jepsen KJ, et al. Serum IGF-1 affects skeletal acquisition in a temporal and compartment-specific manner. PLoS One 2011; 6: e14762.

35. Elis S, Courtland HW, Wu Y, Rosen CJ, Sun H, Jepsen $\mathrm{KJ}$, et al. Elevated serum levels of IGF-1 are sufficient to establish normal body size and skeletal properties even in the absence of tissue IGF-1. J Bone Miner Res 2010; 25: 1257-1266.

36. Olson LE, Ohlsson C, Mohan S. The role of GH/IGF-Imediated mechanisms in sex differences in cortical bone size in mice. Calcif Tissue Int 2011; 88: 1-8. 